\title{
Experiment on Concrete Containing with Activated Carbon and Nano-Fly ash, Nano Metakaolin
}

\author{
Sai Dinakar Swaroop M, Prince Arul Raj G
}

\begin{abstract}
Concrete is a versatile material having many advantages. Hence it is the most widely used material in the construction industry. Many researchers made attempts to use waste materials with the objective of eliminating the disposal problems and at the same time improving the properties of concrete. An attempt has been made to improvethe compressivestrength of concrete with activated carbon, Nano fly ash (NF) and Nano metakaolin (NM). In this work, the concrete mix was prepared by replacing cement with $20 \%(N F)$ and $10 \%$ (NM). Further, the concrete mix is added with $0.4 \%, 0.8 \%, 1.2 \%$, $1.6 \%, 1.8 \%$ and $2 \%$ of activated carbon. The compressive strengths of cement were evaluated after 28days of curing. It is observed that the concrete mix added with $1.2 \%$ of activated carbon exhibited the maximumstrength. The maximum increase in the strength was found to be $25 \%$ more than that of the concrete without Activated Carbon.
\end{abstract}

Keywords: Activated Carbon, Nano Fly-ash, Nano Metakaolin

\section{INTRODUCTION:}

Concrete is a widely used construction material. Using mineral supplementary cementitious materials such as Nano fly ash (FA), Nanometakaolin(NM) and activated carbon(AC). Fly ash has been successfully used as supplementary cementing at mixture in concrete and it improves the concrete mechanical properties and durability. Metakaolin is a cementitious material used as an admixture to produce high strength concrete since it has Pozzolanic properties, it can be used as partial replacement of cement materials in concrete. activated carbon is a form of carbon processed to have a small low volume pores that increase the surface area. It is a finer and coarser material made up of crushed or ground carbon particles

\section{PROPERTIES OFMATERIALS:}

\section{Cement:}

53 grade ordinary Portland cement was used. The specific gravity of cement was 3.15

\section{Manufacturedsand}

Manufactured sand is obtained from crushing hard rock's using heavy machinery. It is finely graded and cubical in shape. Required grade of sand for the given purpose helps the concrete more compact, thus increasing the strength of concrete.

Revised Manuscript Received on April 12, 2019.

Sai Dinakar Swaroop M, M Tech Student, Engineering and Technology, Karunya Institute of Technology and Sciences, Coimbatore641114, T.N, India

Prince Arul Raj G, Professor \& Dean, Engineering and Technology, Karunya Institute of Technology and Sciences, Coimbatore-641114, T.N, India
Table 1: Properties of manufactured sand

\begin{tabular}{|c|c|c|}
\hline S/N & Property & Value \\
\hline 1 & Specific gravity & 2.70 \\
\hline 2 & Water absorption & $6.7 \%$ \\
\hline
\end{tabular}

\section{Coarse aggregate}

In this investigation, coarse aggregate is passes through $20 \mathrm{~mm}$ sieve and retained on $16 \mathrm{~mm}$ sieve. Well graded cubical or rounded coarse aggregates are desirable. Specific gravity of coarse aggregate used here is 2.80 .

Water:

Water is the one of the major constituents of preparing concrete as well as curing. The water using for concrete mixing should be free from alkalis, oils, acid, organic materials etc. Generally potable water is considered for concrete mixing.

\section{Activated carbon:}

Activated carbon, also called activated charcoal, is a form of carbon processed to have small, low-volume pores that increase the surface area.it is a waste material used for construction purposes.

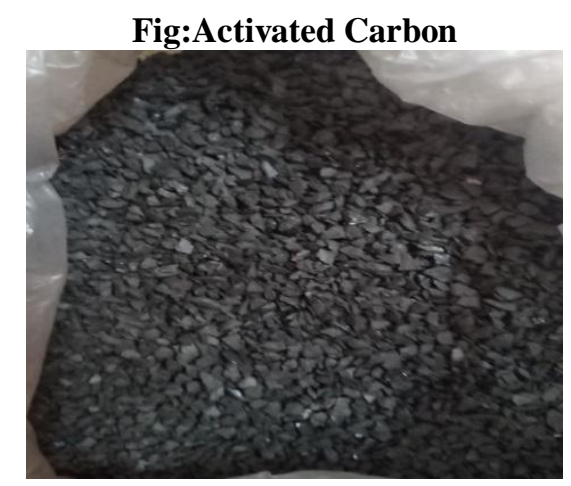

Nano fly ash:

Flyash is used as a supplementary cementitious material (SCM) in the production of Portland cement concrete. A supplementary cementitious material when used in conjunction with Portland cement contribute to the properties of the hardened concrete. Present days construction industries need faster development and also require high strength of concrete to facilitate the fast and economic construction. This demand of high early strength grain of concrete put forth the use of low w/c ratio.

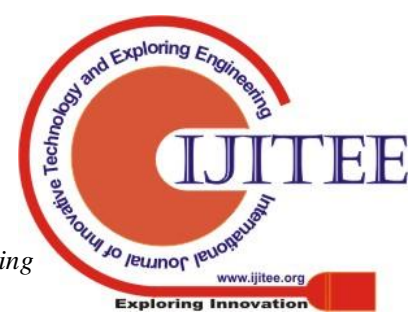




\section{Experiment on Concrete Containing with activated carbon and \\ Nano-fly ash, nano metakaolin}

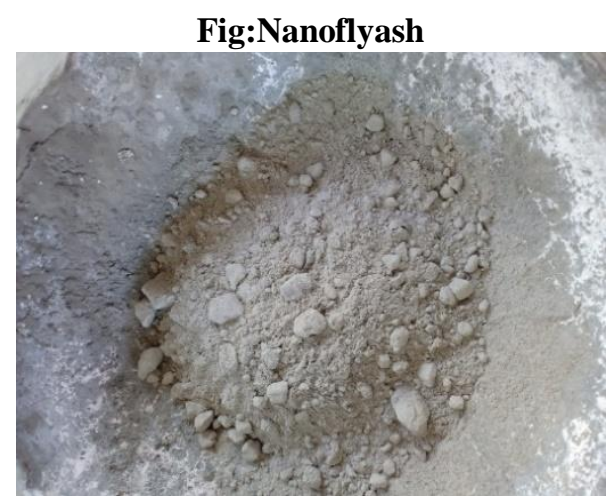

Nano metakaolin:

Nano metakaolin is the anhydrous calcined form of the clay mineral kaolinite. Minerals that are rich in kaolinite are known as china clay or kaolin, traditionally used in the manufacture of porcelain. The particle size of metakaolin is smaller than cement particles, but not as fine as silica fume.it increases the compressive strength and flexural strength and enhanced workability and finishing of concrete.it performance is higher strength and lightweight in concrete

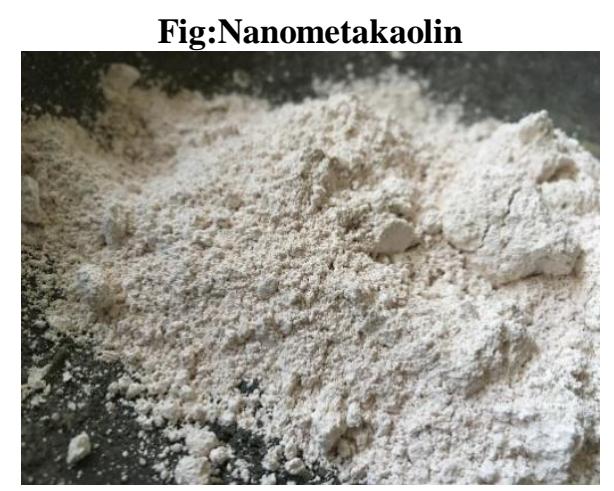

\section{LITERATURE REVIEW:}

Mehrdad, have shown that the highest strength obtained for $20 \%$ fly ash cement mortar was found at $1.2 \%$ activated carbon and the compressive strength after 28days was $22.39 \mathrm{mpa}$, along with compressive strength of the composites were investigated. Results showed that the addition of activated carbon in the fly ash cement improved the fly ash, cement compressive strength is increased. Their study provides mechanical properties of Nano fly ash and cement provided. The air void characteristics and consequent replacement at $20 \%$ of cement and Nano fly ash at the laboratory are collected from the industry. Overall the Activated Carbon decreases the air void content typically ranges from the affected specific area and spacing factor determined. This also includes the PAC effects added to the concrete mix in laboratory directly collected with fly ash were considered for determining the samples in the laboratory $\mathrm{AC}$ content in mixes of containing fly ash resulted in a decrease in the fresh air void content.

\section{Chao can Zheng, (2017)}

This study's shows that the highest strength obtained for $20 \%$ flyash cement was found at $4 \%$ activated carbon and the compressive strength after 28days was $22.39 \mathrm{mpa}$, the compressive strength of the composites were investigated. Composite Materials is not adding activated carbon fly ash their cement microstructure and higher strength is denser. Results show that the addition of activated carbon in the fly ash cement mortar can improve the fly ash, cement mortar compressive

The strength of concrete dense. Results show that the addition of activated carbon in the Fly ash cement mortar can improve the fly ash, cement in compressive strength

\section{Ismael[2017]}

This study's that Increases in both compressive and tensile strength resulted from GAC incorporation, These results prompt the following substitution of conventional fine aggregate materials with low cost, light weight carbonaceous aggregate. it appears internal curing enhancement by GAC particles decrease in compressive strength which results from replacing of silica sand grains with weaker GAC,it provide the large specific surface area hosted by GAC. It shows the segmenting may occur in cure mortar when hydrated GAC is substituted for fine aggregate in certain mass ranges.

\section{T.Panyathanmaporm[2018]}

This studysScience most literatures reported the optimum activation temperature for biomass generally falls between 400 and 500deg, were evaluated for this study. Activated carbon using direct methods such as utilizing actual images obtained using high magnification microscopes.

The commonly applied to the adsorption to calculate the specific surface area and analysis to lead to obtaining the pores diameters.

\section{M.V.A.Florea,(2014)}

This study's One way to do this is by replacing cement with a suitable material; in this research, recycled concrete fines obtained from crushed concrete (RCF) is used to replace part of the cement in new mortar.

It was demonstrated in this study that untreated and 800 ${ }^{\circ} \mathrm{C}$-treated RCF can be used to replace up to $20 \%$ of the cement in standard mortar samples without a significant loss of strength view the same effect was observed when the replacement of $30 \%$ of cement was attempted by all consideration particles

\section{Mohammad,(2018)}

In this research, the mechanical properties of experimental tests including electrical resistivity, temperature raising through microwave heating, indirect tensile. The effects of damage level, effective healed length, and test temperature on the induced healing of cracked asphalt specimens under breaking-healing cycles were discussed The effects of the sample dimension on induced heating of the conconcretes were investigated. The experimental results and proposed mechanical-empirical model indicated that for a specific length. trol and AC modified asphalt increasing the breaking-healing cycle, the damage density of the asphalt concrete increases and $\mathrm{HI}$ decreases.

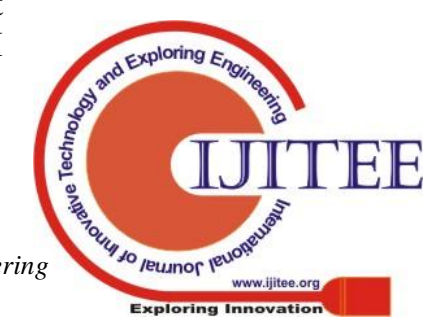




\section{Sumit Chakraborty,(2014)}

This study's in this investigation, concrete samples were fabricated using variable amounts of aggregates and alkali activator content Effectiveness synthesized Nano cement on mechanical performances of concrete. Reduction of $\mathrm{CO} 2$ emission during cement production utilizes Effective reduction of curing period. it is assessed that the Nano cement based concrete fabricated using the optimum amount of fine aggregate $(516 \mathrm{~kg} / \mathrm{m} 3)$, coarse aggregate (804 $\mathrm{kg} / \mathrm{m} 3)$ and alkali activator content $(440 \mathrm{~kg} / \mathrm{m} 3$ alkali activator) showed superior mechanical performance as compared to that of the other concrete mix design.

\section{Konstantin Kovler,(2011)}

This paper shoes that the In order to keep similar properties in terms of durability, setting time and mechanical strength, the water amount in the system is also reduced. develope new methods of testing, interpret test results, model and predict the developments, such as lightweight, self-compacting, fiber-reinforced, highstrength, high-performance and other types of concrete. It seems that the number of such publications will be growing further number of properties

\section{FilizKaracan,(2007)}

This study is attempted to understand that activated carbon in order to process that can be obtain a high yield and well developed porosity. experimental results were obtained by carbon yield $38.15 \%$. Surface area 910 , total pore volume 0.572 these results were processing that performing of activated carbon under the optimum condition to determine the effect of chemical composites.Lignite is the good precures for the production of activated carbon with well porosity. Activated carbon with the high porosity are extensively used a in this process, its availability is cheapness

\section{METHODOLOGY:}

The methodology adopted for the current experimental investigation is:

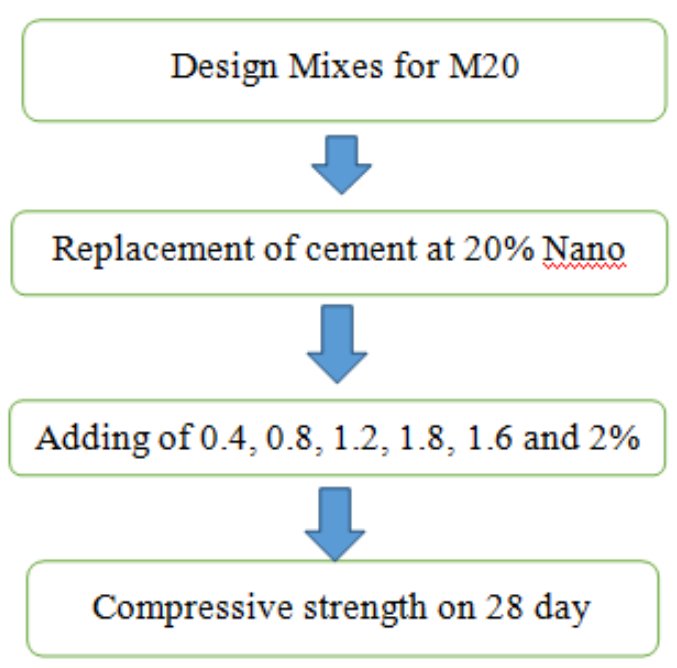

The design mix for grade M20 will be the replacement of cement were prepared the percentage namely such as $20 \%$
Nano fly ash and $10 \%$ of Nanometakaolin due to the addition of activated carbon specimens for compressive strength tested for 28days After curing the cubes were tested using a compression testing machine. These cubes were loaded on their sides during compression testing such that the load was exerted perpendicularly to the direction of casting.

\section{EXPERIMENTAL INVESTIGATION:}

\section{Compression Test:}

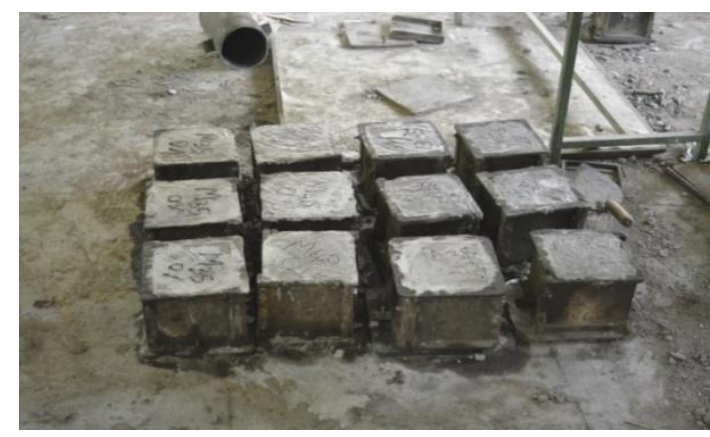

Activated Carbon was purchased from construction Industry. Nano fly ash (NF),Nanometakaolin (NM) $20 \%$ (NF) $10 \%$ (NM) cement $80 \%$ ordinary Portland cement ratio was obtained. In a comparative study with ordinary Portland cement performance, while first using an Nano fly ash (NF) and Nano metakaolin (NM) then mix by adding of activated carbon to a portion of cement. These materials were mixed together to form cubes of sizes 150x150x150xmm were cured after removal, cement test block at room temperature water conservation respectively 28days measuring its compressive strength.
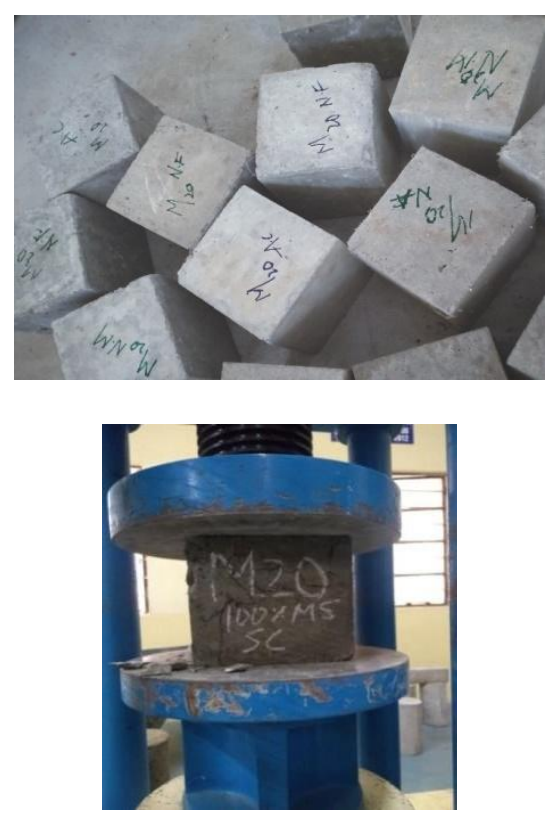

Procedure:

- Cubes were weighed before loading.

- The cubes are placed in the compressive testing machine and the load was applied gradually.

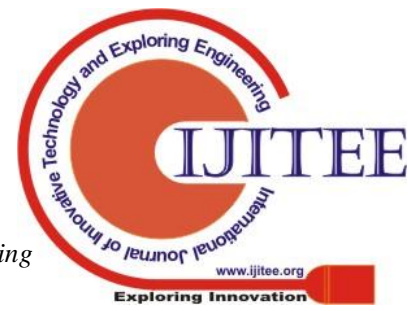




\section{CONCLUSION:}

- The digital machine shows the amount of load applied on the display.

- Care was taken that the load is applied at a uniform rate.

- The load reaches a maximum point and starts reducing thereafter. The maximum load is the ultimate load and that reading was note

Table 1: The details of the mix design are given in table below:

\begin{tabular}{|c|c|c|c|}
\hline $\begin{array}{c}\text { Water } \\
\text { Cement } \\
\text { Ratio }\left(\mathrm{kg} / \mathrm{m}^{3}\right)\end{array}$ & $\begin{array}{l}\text { Cement } \\
\left(\mathrm{kg} / \mathrm{m}^{3}\right)\end{array}$ & $\begin{array}{c}\text { Fine } \\
\text { Aggregate } \\
\left(\mathrm{kg} / \mathbf{m}^{3}\right)\end{array}$ & $\begin{array}{c}\text { Coar se } \\
\text { Aggregate } \\
\left(\mathrm{kg} / \mathrm{m}^{3}\right)\end{array}$ \\
\hline 186 & 394.32 & 669.527 & 1159.61 \\
\hline 0.5 & 1 & 1.55 & 3.1 \\
\hline
\end{tabular}

\section{RESULT AND DISCUSSIONS:}

The results of compressive strength test measurements a of M20 grade concrete specimens mixed with the combination of Nano fly ash, Nano metakaolin and activated carbon.

\begin{tabular}{|c|c|c|}
\hline $\begin{array}{c}\% \text { material added and } \\
\text { replaced }\end{array}$ & $\operatorname{load}(\mathrm{kN})$ & $\begin{array}{c}\text { compressive } \\
\text { strength }\left(\mathrm{N} / \mathrm{mm}^{2}\right)\end{array}$ \\
\hline Reference & 595.58 & 26.48 \\
\hline $10 \% \mathrm{NM}+20 \% \mathrm{NF}+0.4 \% \mathrm{AC}$ & 620.55 & 27.58 \\
\hline $10 \% \mathrm{NM}+20 \% \mathrm{NF}+0.8 \% \mathrm{AC}$ & 662.17 & 29.43 \\
\hline $10 \% \mathrm{NM}+20 \% \mathrm{NF}+1.2 \% \mathrm{AC}$ & 736.87 & 32.75 \\
\hline $10 \% \mathrm{NM}+20 \% \mathrm{NF}+1.6 \% \mathrm{AC}$ & 683.15 & 30.36 \\
\hline $10 \% \mathrm{NM}+20 \% \mathrm{NF}+1.8 \% \mathrm{AC}$ & 668.92 & 29.73 \\
\hline $10 \% \mathrm{NM}+20 \% \mathrm{NF}+2 \% \mathrm{AC}$ & 610.87 & 27.15 \\
\hline
\end{tabular}

Table 2:Tabulation of mix proportion for M20Tabel given below:

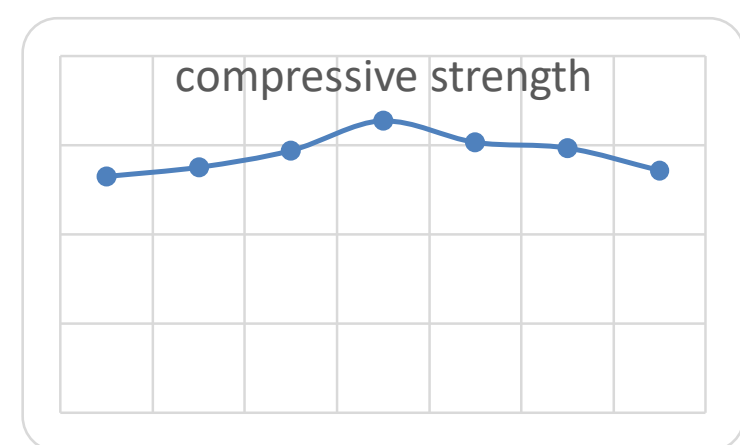

Figure 1: Compressive strength of concrete specimen cured for $28 d a y s$.

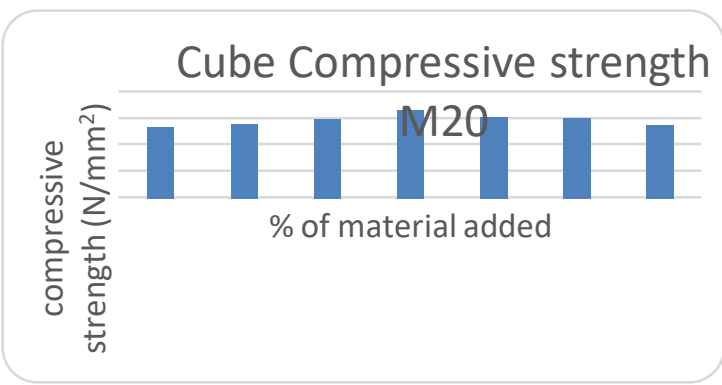

Figure 2:Compressive strength of activated carbon Nano fly ash
An experimental investigation was carried to study the significance of the conclusion

The result M20 shows that the addition of activated carbon for Nano fly ash and Nano metakaolin in the cement can improve compressivestrength of the concrete. The strength increases with activated carbon $20 \%$ Nano flyash (NF) $+10 \%$ Nano metakaolin(NM) and $1.2 \%$ of activated carbon cement highest 28thday compressive strength value $32.75 \mathrm{Mpa}$ of the optimum value of significant. Incorporation of $20 \%$ and $10 \%$ and $0.4 \%$ addition of mixes in the cement the $28^{\text {th }}$-day compressive strength $26.48 \mathrm{MPa}$. Reference value considerably

Based on the above discussion combination of Nano fly ash and Nanometakaolinwith addition of Activated Carbon can improve compressive strength of concrete and more reliable results to study the analysis of low-cost method of rapid assessment of air void in hardened concrete, therefore it shows from the above result the impact on the compressive strength is more compared to reference specimen

\section{REFERENCE:}

1. Mehrdad:Effect of powdered activated carbon on the air void characteristics of concrete containing fly ash,Year(2015)

2. ChaocanZheng:Compressive strength and microstructure of activated carbon fly-ash cement composites,year(2017)

3. Ismael: Fine aggregate substitution by granular activated carbon can improve physical and mechanical properties of cement mortars,year(2018)

4. T.Panyathanmaporm-Production of activated carbon from coconut shell:

5. M.V.A.Florea,:Activation of liberated concrete fines and their application in mortars.

6. Mohammad:Induced heating-healing characterization of activated carbon modified asphalt concrete under microwave radiation, Year(2018)

7. Sumit Chakraborty:Investigation on the effectiveness of chemically synthesized Nano cement in physical and mechanical performances of concrete, Year(2014)

8. Konstantin Kovler: Properties' of fresh and hardened concrete .Year(2011) 